\title{
Cost-effectiveness of next-generation vaccines: the case of pertussis
}

Meagan C. Fitzpatrick, ${ }^{1, \bowtie}$ Natasha S. Wenzel, ${ }^{1,2}$ Samuel V. Scarpino, ${ }^{3}$ Benjamin M. Althouse, ${ }^{3,4,5}$

Katherine E. Atkins, ${ }^{6}$ Alison P. Galvani, ${ }^{1}$ Jeffrey P. Townsend ${ }^{7}$

${ }^{1}$ Center for Infectious Disease Modeling and Analysis, Yale School of Public Health, New Haven, CT, USA

${ }^{2}$ Center for Inference and Dynamics of Infectious Disease, Fred Hutchinson Cancer Research Center, Seattle, WA

${ }^{3}$ Santa Fe Institute, Santa Fe, NM

${ }^{4}$ Institute for Disease Modeling, Bellevue, WA

${ }^{5}$ New Mexico State University, Las Cruces, NM

${ }^{6}$ Department of Infectious Diseases, Faculty of Epidemiology and Population Health, London

School of Hygiene and Tropical Medicine, London, UK

${ }^{7}$ Department of Biostatistics, Yale School of Public Health, New Haven, CT, USA

$\bowtie$ Direct correspondence to meagan.fitzpatrick@yale.edu; 135 College St, Suite 200, New Haven,

CT 06510; Phone: (203) 909-0174 


\section{Abstract}

Despite steady vaccination coverage rates, pertussis incidence in the United States has continued to rise. This public health challenge has motivated calls for the development of a new vaccine with greater efficacy and duration of protection. Any next-generation vaccine would likely come at a higher cost, and must provide sufficient health benefits beyond those provided by the current vaccine in order to be deemed cost-effective. Using an age-structured transmission model of pertussis, we quantified the health and economic benefits of a next-generation vaccine that would enhance either the efficacy or duration of protection of the childhood series, the duration of the adult booster, or a combination. We developed a metric, the maximum cost-effective price increase (MCPI), to compare the potential value of such improvements. The MCPI estimates the per-dose price increase that would maintain the cost-effectiveness of pertussis vaccination. We evaluated the MCPI across a range of potential single and combined improvements to the pertussis vaccine. As an upper bound, we found that a next-generation vaccine which could achieve perfect efficacy for the childhood series would permit an MCPI of $\$ 18$ per dose (95\% CI: \$12-\$31). Pertussis vaccine improvements that extend the duration of protection to an average of 75 years would allow for an MCPI of \$22 per dose for the childhood series (CI: \$10\$33) or $\$ 12$ for the adult booster (CI: \$4-\$18). Despite the short duration of the adult booster, improvements to the childhood series could be more valuable than improvements to the adult booster. Combining improvements in both efficacy and duration, a childhood series with perfect efficacy and average duration of 75 years would permit an MCPI of \$39 per dose, the highest of any scenario evaluated. Our results highlight the utility of the MCPI metric in evaluating potential vaccines or other interventions when prices are unknown. 


\section{Keywords}

cost-effectiveness, mathematical modeling, pertussis, price, vaccine 


\section{Introduction}

A resurgence of pertussis in the United States (US) has resulted in the highest incidence in over half a century $[1,2]$. Several hypotheses have been postulated to explain the rising incidence [36], with the prevailing view that the increase is attributable to shortcomings in the current vaccine series $[7,8]$. The acellular pertussis $(\mathrm{aP})$ vaccines currently used in the US are the second generation of pertussis vaccines, licensed during the 1990s in response to concerns about severe side effects associated with whole-cell containing (wP) vaccines [9]. Elevated pertussis in adolescents, who represent the first cohorts vaccinated with the aP vaccine, has led to the suggestion that the protection conferred by the acellular vaccines wanes faster than that of the wP vaccines [10-12]. Additionally, the first doses in the acellular childhood series at 2 and 4 months confer incomplete protection against disease for infants, who have the highest burden of severe pertussis-related disease and mortality $[13,14]$. Recent studies have demonstrated that administration of a maternal pertussis booster vaccine during pregnancy substantially and costeffectively reduces disease burden in newborns prior to receipt of their first dose [15-17]. Nevertheless, the apparent shortcomings of the current childhood and adult vaccination series have renewed interest in a next generation of pertussis vaccine that would provide higher efficacy for infants, a longer duration of protection, or both $[7,8]$.

If such an improved vaccine were brought to market with a price per dose equal to the current vaccine, the decision to switch to the new vaccine would be straightforward. However, the investment that would be required to develop a new vaccine entails a higher cost per dose than that for the current vaccines. Additionally, new recommendations for maternal aP vaccination during pregnancy for infant protection $[15,16]$ may render any health benefits of a new vaccine insufficient to justify the increased cost. 
Cost-effectiveness analysis is often conducted when considering the implementation of a vaccine that has already been developed [18-22], or hypothetical vaccines against pathogens for which no vaccine exists [23-29]. While — for instance — a study of adding protection against multiple pathogens causing otitis media to the pneumococcal vaccine has identified break-even and costeffective thresholds in vaccine price [30], no previous analysis has assessed the potential health impact and economic value of replacing a current vaccine with an improved hypothetical vaccine. With pertussis - and in similar cases where the current vaccine may have multiple shortcomings — calculating the relative value of improvements in either duration or efficacy could inform the design of a next generation vaccine to optimize public health benefit.

Here, we use a previously validated dynamic cost-effectiveness model of B. pertussis transmission in the US [17] to evaluate the potential health benefits and economic value of developing a next-generation pertussis vaccine. We consider three potential improvements: 1) increased efficacy of the childhood vaccination series, 2) extended duration of protection for the childhood series, and 3) extended duration of protection for the adult booster, as well as combinations of improvements. We formulate the maximum cost-effective price increase (MCPI), as a metric of the value of a new vaccine under the constraint that the vaccine remains cost-effective. The MCPI metric has general applicability to inform decision-making regarding investment in the development and the pricing of potential vaccines.

\section{Methods}

\section{Transmission Model Structure}

We modeled the epidemiological states (Figure 1) as susceptible (S), infectious (T: typical infection, defined in the Acellular Pertussis Vaccine Trial (APERT) as a cough lasting at least six days [31]; A: atypical infection, all other cases), recovered (R), and vaccinated ( $\mathrm{V}_{\mathrm{P}}$ : DTaP 
vaccination, $\mathrm{V}_{\mathrm{B}}$ : Tdap vaccination), keeping track of the participation of parents and their infants in a program of parental vaccination [17]. A model population of 316 million individuals was age-stratified to reflect the 2013 US population [32]. We specified the force of infection for each age class based on empirical age-specific social contact rates for the US [33]. We also incorporated parents of newborns, and parameterized the extensive contacts that they have with their infants based on time-use studies conducted in the US [17,33].

\section{Parameterization and Fitting}

Our base case and uncertainty distributions for epidemiological and economic parameters (Tables S1, S2) were provided by fitting our model to US incidence data from 2003-2012 [1]. We used empirically-derived reporting rates for typical infections for four age groups: $1.38 \%$ for $<1$ years, $0.93 \%$ for $1-6$ years, $0.45 \%$ for $7-10$ years, and $0.30 \%$ for $11+$ years) [17]. We assumed that the less severe atypical cases were neither hospitalized nor reported.

\section{Scenarios of Next-Generation Pertussis Vaccines}

Scenarios for improvement of the pertussis vaccine included: 1) increasing the efficacy of the childhood vaccination series, 2) extending the duration of protection for the childhood series, and 3) extending the duration of protection for the adult booster.

We define efficacy, $E$, as the proportional reduction in the risk of infection for vaccinated individuals relative to that of a susceptible, unvaccinated individual [34]. We parameterize the efficacy of each of the first three doses of the pertussis vaccine using data from a case-control study [13]. These case-control studies characterize effectiveness rather than efficacy at the time 
of vaccination; however, under the assumption that no waning occurs in the time between the administration of each of the three primary doses, vaccine effectiveness and efficacy are equivalent. Efficacy for the fourth and fifth dose was calculated previously [17] by simultaneously fitting both efficacy and duration to case-control data $[12,13]$. To model an improvement to efficacy, we simultaneously increased the efficacy of each dose by a factor $p$, such that

$$
E_{n}^{(i)}=1-\left(1-E_{c}^{(i)}\right) / p
$$

where $E^{(i)}{ }_{n}$ is the efficacy of a the $i$ th dose of the next-generation vaccine, and $E^{(i)}{ }_{c}$ is the efficacy of the $i$ th dose for the current vaccine. Protection from the fourth and fifth doses of the childhood series is estimated to be complete prior to waning, as is protection from the adolescent and adult booster [17]. We evaluated our model across a range of first-dose efficacy from its current estimated value, 0.55 , up to a perfect efficacy of 1.

Waning of efficacy was modeled as an exponential function, with a base case average duration of 25 years for the complete childhood series [12,17], and 2.7 years for each adult booster [17]. These 'durations' are modeled as the inverse of the waning rate, and were calculated previously by fitting to case-control data $[11,12,17]$. They are consistent with waning rates estimated by others $[35,36]$. The exponential waning process in the model does not yield complete protection for all individuals for the duration. Indeed, with an average duration of immunity of 25 years, nearly one-third of vaccinated individuals will have lost their immunity within 10 years of their most recent dose. No matter the duration, waning begins immediately following vaccination, following a "deterioration" model [37]. Next generation vaccines were evaluated for average durations of protection up to 75 years for both childhood and adult vaccination. Given that the intervals between the first four doses of the childhood series are much shorter than the average 
duration of protection conferred and that series completion rates are high, changes to the duration of protection will not greatly benefit infants before receipt of the fourth dose. Therefore, we assumed improvements regarding the duration of protection apply to the final two doses in the childhood series $\left(\mathrm{V}_{\mathrm{P} 4} \& \mathrm{~V}_{\mathrm{P} 5}\right)$ and/or the adult booster (B). Additionally, we evaluated scenarios of simultaneous improvement in the efficacy and duration of the childhood series, as well as a scenario of simultaneous improvement in the duration of protection for both the childhood and adult boosters.

We modeled the current childhood schedule of doses at 2, 4, 6, and 18 months, and 5 years old [38]. We also included an adolescent booster at 12 years old and a booster for women during the third trimester of each pregnancy $[39,40]$. We applied current estimates of coverage in the US for the childhood series and the adolescent booster [41]. Coverage estimates for Tdap during pregnancy in the US vary substantially across studies, from less than $20 \%$ [42] to over $80 \%$ [43]. In our base case, coverage for maternal vaccination was set at $50 \%$. A coverage of $50 \%$ is currently achieved in pregnant women for the influenza vaccine [44], which has been recommended for pregnant women in the US since 2004. Our sensitivity analysis considers the outcomes at both higher and lower coverage levels for maternal vaccination. In our model, U.S. maternal vaccination begins in 2013 .

We compared the predictions for 2020-2030 with each next-generation vaccine against predictions for the same time period retaining the current vaccine. Consistent with US demographic trends, we specified four million infants be born annually and become eligible for pertussis vaccination [45].

Maximum Cost-Effective Price Increase 
According to cost-effectiveness criteria set by the World Health Organization (WHO), an intervention is considered "cost-effective" if it confers health benefits at a cost less than three times the per-capita gross domestic product (GDP) per life-year [46]. For the US in 2013, this threshold is $\$ 159,429$. Following this criterion, the maximum cost-effective price increase (MCPI) for a next generation booster would be:

$$
\frac{Q \times w+M}{d},
$$

where $Q$ is the number of quality-adjusted life-years (QALYs) saved through use of a new vaccine, $w$ is the willingness-to-pay for life-years, $M$ is the economic savings from reduced medical costs of disease, and $d$ is the number of vaccine doses that are delivered. Indirect costs associated with vaccination or disease are not included here, but would be considered a component of $M$. While improved efficacy pertains only to the primary three doses of the childhood series, and improved duration pertains only to the fourth and fifth doses of the childhood series, the cost increase is assumed to be spread across all five doses of the series. Costs and QALYs were discounted by 3\% annually over the decade time frame [46], but costs and QALYs were assumed constant over the period prior to implementation of the nextgeneration vaccine. Therefore, all costs are presented in 2013 \$US.

\section{Results}

We found that improved efficacy of the vaccine doses in the childhood pertussis series would provide nearly linear gains in health and economic returns. For example, an increase in the efficacy of the first dose from 0.55 to 0.75 , with proportional increases in the efficacies of other childhood doses, would provide an average gain of 900 QALYs annually during the first 10 
years following implementation (Figure 2, Table 2), averting \$5.7 million in health expenditures annually. If the first dose of the childhood series were perfectly efficacious, it would provide an average gain of 2100 QALYs annually over a decade and health savings of $\$ 12.9$ million annually. These gains provide an upper bound for what a vaccine with improved efficacy could do: the maximum cost-effective price increase (MCPI) per dose would be $\$ 8$ per dose with a first-dose efficacy of $75 \%$, and $\$ 18$ for $100 \%$ efficacy.

In contrast to improvements in vaccine efficacy, extension of the vaccine duration of protection provided by the childhood series exhibited diminishing marginal returns. Increasing the average duration of protection conferred by the childhood series from 25 years to 50 years would provide an average annual gain of 1800 QALYs and annual health savings of \$6.3 million. In comparison, extending the average duration further to 75 years would provide an average annual gain of 2600 QALYs and an annual health savings of $\$ 8.7$ million. The MCPI per dose for a more durable childhood vaccine would be $\$ 16$ for a duration of 50 years, and $\$ 22$ for a duration of 75 years. Largely due to the uncertainty surrounding the protective duration of the current vaccine, the lower bounds for the $95 \%$ confidence intervals on QALYs gained and of the MCPI are not positive until the duration of protection of the next-generation vaccine reaches approximately 35 years.

Extension of the average duration of the adult booster from 2.7 years to 30 years would provide an annual gain of 300 QALYs and annual health savings of $\$ 1.3$ million. The benefits of increasing the duration of protection for the adult booster quickly plateau. Extension of its duration by an additional 45 years, to 75 years, provides an annual gain of 400 QALYs and an annual health savings of $\$ 1.5$ million: an increase of only 100 QALYs and $\$ 200,000$ annually despite the fact that the duration has been extended by an additional 45 years. Following the 
same trend, the MCPI per dose would be $\$ 11$ for a duration of 30 years, and only modestly increases to $\$ 12$ for a vaccine with an average duration of 70 years.

Concurrent improvement to both the efficacy and duration of the childhood vaccine predictably achieves the maximum health benefit of all scenarios tested (Figure 3b, 3d). The combination of improvements that achieves both the greatest health benefits and the highest MCPI would be a childhood series with perfect efficacy and a 75-year average duration of protection, which could provide an average annual gain of 4600 QALYs at an MCPI of \$39. Improving the duration of both the childhood and adult vaccine also has the potential to achieve greater health benefits than improvement in any single factor, and could warrant a higher price (Figure 3a, 3c). However, the MCPI for any combination of improvements is less than the sum of the individual MCPIs for the improvements which make up the combination.

The MCPI is sensitive to the societal willingness-to-pay (WTP) for QALYs. For improvements to childhood vaccine efficacy, the MCPI at a willingness-to-pay of \$0 per QALY is approximately $4 \%$ of the MCPI at a WTP of $\$ 150,000$ per QALY (Figure 4), indicating that nearly all of the value for this improvement is derived from QALY benefits rather than monetary health savings. The MCPI for extended duration is also sensitive to WTP. The value of the MCPI is robust to shifts of maternal vaccination coverage, particularly to any expansion above the current coverage of 15\% (Supplementary Figure 1).

\section{Discussion}

We have performed the first quantitative analysis of the potential utility and value of introducing a next-generation vaccine. Increasing the efficacy of the childhood pertussis vaccine series, 
extending the duration of protection of the childhood vaccines, or extending duration of protection for the adolescent and adult boosters could all improve health and avert medical costs as stand-alone improvements or in combination. The singular improvement to pertussis vaccines that would provide both the greatest potential health benefit and the greatest economic benefit would be extending the duration of protection of the childhood vaccine series. Increasing the efficacy of the childhood series could also provide substantial benefit; however, the benefits of extending the duration of protection of the adult booster would not convey as much benefit as would be conveyed by improvements to the childhood series. The combination of improving the childhood series to perfect efficacy and an average 75-year duration of protection achieves both the largest health benefits and the highest MCPI, \$39. This MCPI represents the upper bound of a cost-effective price increase for a new vaccine.

Given that the average duration of protection for the adult booster is less than 3 years, it might be expected that the improvements to the duration of protection for the adult booster would yield the greatest returns. Indeed, our results demonstrate that small improvements to the durability of the adult booster vaccine would be more valuable than an equivalent improvement to the childhood series. However, the benefits of extending protection of the adult booster quickly plateau, and are eclipsed by the benefits of improving the efficacy and duration of the childhood series. For example, a five-year extension of protection to the adult booster would convey greater value than a five-year extension to the childhood series. In contrast, a 25-year extension of protection of the childhood series would have greater health and economic impacts than a 25year extension to the adult booster. These results provide insight into the potential returns on technological development.

There is considerable uncertainty surrounding the duration of protection of the childhood series [12]. We have incorporated the uncertainty regarding this parameter in our analysis, conveying 
insight into the minimum improvement in duration of protection that would be necessary for the next-generation vaccine to be economically valuable. At a 35-year duration of protection the lower $95 \%$ confidence interval becomes positive, indicating that a price increase based on extended durability may only be justifiable if the new childhood series demonstrably exceeds this mark. In contrast, small improvements to the duration of protection of the adult booster and to the efficacy of the childhood series quickly and confidently generate a positive MCPI. Health and economic outcomes quantified by the epidemiological model underlying this analysis are robust to reasonable variation in diverse other epidemiological parameters such as the duration of natural immunity, the relative infectiousness of an asymptomatic case compared to a typical one, social contact rates, and others [17].

Exponential waning of protection models individual heterogeneity, whereby some individuals lose their immunity almost immediately and others retain protection for considerably longer than the mean. Indeed, under our base case estimate that the duration of the childhood series has a mean of 25 years, nearly one-third of vaccinated individuals have lost their immunity within 10 years of their most recent dose. This duration of protection leaves considerable room for improvement. For example, with a mean duration of protection of 75 years, less than $15 \%$ of individuals would lose their immunity within 10 years of their most recent dose.

Maternal vaccination during pregnancy has been shown to significantly reduce the risk of pertussis infection in newborns [15]. Despite the strong protection conferred by maternal vaccination to infants, our results are robust to changes in maternal vaccination coverage. This robustness is largely attributable to the benefits of maternal vaccination for infants under two months old. This newborn age class is largely unaffected by the improvements investigated here as they remain unvaccinated. 
Recent studies suggest that Bordetella pertussis may be evolving antigenically to evade protection by the current vaccine [47]. As resistant Bordetella pertussis pathogens proliferate, the efficacy and duration of the the current vaccine will be further reduced. A next-generation pertussis vaccine could specifically alleviate these issues. Alternatively, the current generation of vaccine might be improved in ways that are not captured by higher efficacy and longer duration. Recent studies in non-human primates have shown that aP vaccines protected subjects from typical whooping cough disease but not ongoing transmission [48][49][48] Above all, to be considered acceptable for implementation, any next-generation vaccine would have to demonstrate the same or greater vaccine safety profile compared to existing vaccines.

New vaccines against pertussis are under active development. A phase I clinical trial recently demonstrated the safety of a live-attenuated nasal pertussis vaccine based on the BPZE1 strain [50]. Mouse studies suggest that this vaccine might have higher efficacy in infants than the current acellular vaccine [51]. If perfect efficacy could be achieved at the first infant dose, the MCPI of this new vaccine would be $\$ 18$. If the vaccine improved duration of protection as well, a higher price would be warranted. Identification of alternative vaccine candidates is ongoing $[52,53]$. As yet, information regarding the potential efficacy or waning of these candidates is unavailable.

Economic predictions for future vaccines have focused on the potential cost-effectiveness of introducing vaccination where none currently exists [19,20,25,28]. Our analysis provides the first quantification of the value of replacing an existing vaccine with a hypothetical higher-cost, higher-performing option. The metric we have developed, the maximum cost-effective price increase (MCPI), is readily applicable to analyses of improvements to vaccines against other diseases. Such analyses could be informative for many different stakeholders in vaccinology. Scientists can be guided to the most impactful avenues for research. On the other hand, the 
vaccine with the highest MCPI does not necessarily provide the greatest health benefits. For example, if the willingness-to-pay for QALYs was sufficiently low, and if the medical costs of disease treatment in a population subset were sufficiently high, the vaccine with the highest MCPI would not align with the vaccine providing the greatest health benefits. Manufacturers gain information about potential investments and avoid fruitless expenditure. Using MCPI, manufacturers and purchasers can enter into price negotiations with more complete information, enabling a more efficient and transparent market. Most importantly, patients will receive the direct health benefits from an improved next-generation pertussis vaccine.

\section{Acknowledgments}

MCF, NSW, APG, and JPT were funded by the Notsew Orm Sands Foundation. MCF, APG, and JPT also received funding from Merck \& Co., Inc. SVS and BMA were funded by the Santa Fe Institute and the Omidyar Group. KEA was funded by the National Institute for Health Research Health Protection Research Unit (NIHR HPRU) in Immunisation at the London School of Hygiene and Tropical Medicine in partnership with Public Health England (PHE). The views expressed are those of the authors and not necessarily those of the NHS, the NIHR the Department of Health or Public Health England.

The funders/sponsors had no role in the design and conduct of the study; collection, analysis, and interpretation of the data; preparation, review, or approval of the manuscript; and decision to submit the manuscript for publication. 
Conflict of Interest: MCF, APG, and JPT received funding from Merck \& Co., Inc. for consultation on pertussis vaccination. MCF, KEA, APG, and JPT have also consulted for Sanofi Pasteur regarding pertussis vaccination. SVS and BMA received funding support from ILiAD Biotechnologies LLC for consultation on pertussis vaccination. 
Table 1: Current vaccine parameter values and ranges evaluated for next-generation vaccine improvements.

\begin{tabular}{|c|c|c|}
\hline Parameter & Current Value & Tested Range \\
\hline \multicolumn{3}{|l|}{ Effectiveness of Infant Series* } \\
\hline Dose 1 & 0.55 & $0.55-1.0$ \\
\hline Dose 2 & 0.75 & $0.75-1.0$ \\
\hline Dose 3 & 0.84 & $0.84-1.0$ \\
\hline Efficacy of Childhood Boosters & 0.98 & $0.98-1.0$ \\
\hline Duration of Childhood Series & 25 years & $25-75$ years \\
\hline Duration of Adolescent/Adult Booster & 2.7 years & $2.7-75$ years \\
\hline
\end{tabular}

*In predictions, the first three doses in the childhood series are improved simultaneously. See Methods for details. 
Table 2: Impact of Individual Improvements for a Next-Generation Vaccine. QALYs, costs, and infant deaths are presented here as annual undiscounted averages. QALYs and costs were discounted at a rate of $3 \%$ annually in the calculation of the maximum cost-effective price increase (MCPI).

\begin{tabular}{|c|c|c|c|c|c|}
\hline Improvement & Value & $\begin{array}{l}\text { QALYs } \\
\text { gained } \\
(95 \% \mathrm{CI})\end{array}$ & $\begin{array}{l}\text { Medical Cost } \\
\text { Savings, in \$US } \\
\text { millions } \\
(95 \% \mathrm{CI})\end{array}$ & $\begin{array}{l}\text { Infant Deaths } \\
\text { Averted } \\
\text { Annually } \\
(95 \% \text { CI) }\end{array}$ & $\begin{array}{l}\text { Maximum } \\
\text { Cost-Effective } \\
\text { Price Increase } \\
(95 \% \text { CI) }\end{array}$ \\
\hline \multirow[t]{4}{*}{$\begin{array}{l}\text { Efficacy of } \\
\text { Childhood Series }\end{array}$} & 0.6 & $\begin{array}{l}200 \\
(30-1400)\end{array}$ & $\begin{array}{l}1.4 \\
(0.8-7.5)\end{array}$ & $\begin{array}{l}0.3 \\
(0.1-1.3)\end{array}$ & $\begin{array}{l}\$ 2 \\
(\$ 0-\$ 12)\end{array}$ \\
\hline & 0.75 & $\begin{array}{l}900 \\
(600-2300)\end{array}$ & $\begin{array}{l}5.7 \\
(4.8-19.0)\end{array}$ & $\begin{array}{l}1.4 \\
(0.9-2.6)\end{array}$ & $\begin{array}{l}\$ 8 \\
(\$ 5-\$ 19)\end{array}$ \\
\hline & 0.9 & $\begin{array}{l}1600 \\
(1100-3100)\end{array}$ & $\begin{array}{l}10.0 \\
(8.2-31.3)\end{array}$ & $\begin{array}{l}2.5 \\
(1.7-4.2)\end{array}$ & $\begin{array}{l}\$ 14 \\
(\$ 9-\$ 26)\end{array}$ \\
\hline & 1 & $\begin{array}{l}2100 \\
(1400-3600)\end{array}$ & $\begin{array}{l}12.9 \\
(10.4-39.3)\end{array}$ & $\begin{array}{l}3.2 \\
(2.1-5.3)\end{array}$ & $\begin{array}{l}\$ 18 \\
(\$ 12-\$ 31)\end{array}$ \\
\hline \multirow{3}{*}{$\begin{array}{l}\text { Duration of } \\
\text { Protection for } \\
\text { Childhood Series }\end{array}$} & 30 & $\begin{array}{l}600 \\
(-400-1700)\end{array}$ & $\begin{array}{l}1.9 \\
(-0.7-3.7)\end{array}$ & $\begin{array}{l}0.3 \\
(-0.3-1.0)\end{array}$ & $\begin{array}{l}\$ 5 \\
(-\$ 4-\$ 14)\end{array}$ \\
\hline & 50 & $\begin{array}{l}1800 \\
(600-3100)\end{array}$ & $\begin{array}{l}6.3 \\
(0.3-8.0)\end{array}$ & $\begin{array}{l}1.1 \\
(0.5-1.7)\end{array}$ & $\begin{array}{l}\$ 16 \\
(\$ 5-\$ 26)\end{array}$ \\
\hline & 75 & $\begin{array}{l}2600 \\
(1200-4000)\end{array}$ & $\begin{array}{l}8.7 \\
(0.5-10.9)\end{array}$ & $\begin{array}{l}1.5 \\
(0.9-2.1)\end{array}$ & $\begin{array}{l}\$ 22 \\
(\$ 10-\$ 33)\end{array}$ \\
\hline \multirow{4}{*}{$\begin{array}{l}\text { Duration of } \\
\text { Protection for } \\
\text { Adolescent/Adult } \\
\text { Booster }\end{array}$} & 10 & $\begin{array}{l}200 \\
(80-300)\end{array}$ & $\begin{array}{l}0.8 \\
(0-1.0)\end{array}$ & $\begin{array}{l}0.2 \\
(0.1-0.2)\end{array}$ & $\begin{array}{l}\$ 7 \\
(\$ 2-\$ 10)\end{array}$ \\
\hline & 30 & $\begin{array}{l}300 \\
(100-500)\end{array}$ & $\begin{array}{l}1.3 \\
(0.1-1.8)\end{array}$ & $\begin{array}{l}0.3 \\
(0.1-0.3)\end{array}$ & $\begin{array}{l}\$ 11 \\
(\$ 4-\$ 16)\end{array}$ \\
\hline & 50 & $\begin{array}{l}400 \\
(100-600)\end{array}$ & $\begin{array}{l}1.4 \\
(0.1-1.9)\end{array}$ & $\begin{array}{l}0.3 \\
(0.1-0.3)\end{array}$ & $\begin{array}{l}\$ 12 \\
(\$ 4-\$ 17)\end{array}$ \\
\hline & 75 & $\begin{array}{l}400 \\
(200-600)\end{array}$ & $\begin{array}{l}1.5 \\
(0.1-2.0)\end{array}$ & $\begin{array}{l}0.3 \\
(0.1-0.4)\end{array}$ & $\begin{array}{l}\$ 12 \\
(\$ 4-\$ 18)\end{array}$ \\
\hline
\end{tabular}

Figure 1: Dynamic Transmission Model Schematic. 
Figure 2: QALY impact and Maximum Cost-Effective Price Increase for three types of next-generation vaccine. Solid lines depict the base case. Dashed lines bound the 95\% confidence interval. QALYs gained (panels A-C, undiscounted annual mean) and the MCPI (panels D-F, costs and QALYs discounted at 3\% annually) are shown for improvements to the efficacy of the childhood vaccine (panels A and D), the duration of the childhood vaccine (panels $\mathrm{B}$ and $\mathrm{E}$ ), and the duration of the adult booster (panels $\mathrm{C}$ and F). For improvements to the efficacy of the childhood series, the efficacy of all doses in the series improves in tandem with improvement to the first dose.

Figure 3: Contour plot of Maximum Cost-Effective Price Increase for next-generation vaccines with combinations of improvements. Contours correspond to the MCPI for improved efficacy and extended duration of the childhood vaccine (A) or for improved duration of both the childhood and adult vaccines (B). For improvements to the efficacy of the childhood series, the efficacy of all doses in the series improves in tandem with improvement to the first dose.

Figure 4: Sensitivity of MCPI to societal willingness-to-pay for QALYs. Each dotted or dashed represents the maximum cost-effective price-increase (\$US) of a single improvement to the pertussis vaccine across varying values for the societal willingness-to-pay for QALYs, a value which corresponds to the threshold for cost-effectiveness. The vertical solid gray line indicates the World Health Organization threshold for cost-effectiveness in the US context: 
$\$ 159,429$ per QALY. For improvements to the efficacy of the childhood series, the efficacy of all doses in the series improves in tandem with improvement to the first dose.

\section{Supporting Information}

Figure S1: Sensitivity of MCPI to maternal vaccination coverage. Each line represents the maximum cost-effective price increase (\$US) of a single improvement to the pertussis vaccine across varying values of maternal vaccination coverage. For improvements to the efficacy of the childhood series, the efficacy of all doses in the series improves in tandem with improvement to the first dose.

Table S1: Epidemiological Model Parameters

Table S2: Historical Vaccination Coverage

Table S3: Health and Economic Outcome Parameters 


\section{References}

[1] Pertussis (Whooping Cough) Surveillance and Reporting. Centers for Disease Control and Prevention n.d. http://www.cdc.gov/pertussis/surv-reporting.html (accessed July 16, 2015).

[2] Skoff TH, Cohn AC, Clark TA, Messonnier NE, Martin SW. Early Impact of the US Tdap vaccination program on pertussis trends. Arch Pediatr Adolesc Med 2012;166:344-9.

[3] Rohani P, Zhong X, King AA. Contact network structure explains the changing epidemiology of pertussis. Science 2010;330:982-5.

[4] Riolo MA, King AA, Rohani P. Can vaccine legacy explain the British pertussis resurgence? Vaccine 2013;31:5903-8.

[5] Rohani P, Pejman R, Earn DJD, Grenfell BT. Pertussis transmission in England and Wales. Lancet 2000;355:1553-4.

[6] Mooi FR. Bordetella pertussis and vaccination: the persistence of a genetically monomorphic pathogen. Infect Genet Evol 2010;10:36-49.

[7] Ausiello CM, Cassone A. Acellular Pertussis Vaccines and Pertussis Resurgence: Revise or Replace? MBio 2014;5:e01339-14 - e01339-14.

[8] Edwards KM. Unraveling the challenges of pertussis. Proc Natl Acad Sci U S A 2014;111:575-6.

[9] Allen A. The Pertussis Paradox. Science 2013;341:454-5.

[10] Winter K, Harriman K, Zipprich J, Schechter R, Talarico J, Watt J, et al. California pertussis epidemic, 2010. J Pediatr 2012;161:1091-6.

[11] Koepke R, Eickhoff JC, Ayele RA, Petit AB, Schauer SL, Hopfensperger DJ, et al. Estimating the effectiveness of tetanus-diphtheria-acellular pertussis vaccine (Tdap) for preventing pertussis: evidence of rapidly waning immunity and difference in effectiveness by Tdap brand. J Infect Dis 2014;210:942-53.

[12] Misegades LK, Kathleen W, Kathleen H, John T, Messonnier NE, Clark TA, et al. Association of Childhood Pertussis With Receipt of 5 Doses of Pertussis Vaccine by Time Since Last Vaccine Dose, California, 2010. JAMA 2012;308:2126.

[13] Quinn HE, Snelling TL, Macartney KK, McIntyre PB. Duration of protection after first dose of acellular pertussis vaccine in infants. Pediatrics 2014;133:e513-9.

[14] Centers for Disease Control and Prevention (CDC). Pertussis--United States, 2001-2003. MMWR Morb Mortal Wkly Rep 2005;54:1283-6.

[15] Amirthalingam G, Andrews N, Campbell H, Ribeiro S, Kara E, Donegan K, et al. Effectiveness of maternal pertussis vaccination in England: an observational study. Lancet 2014;384:1521-8.

[16] Dabrera G, Amirthalingam G, Andrews N, Campbell H, Ribeiro S, Kara E, et al. A case-control study to estimate the effectiveness of maternal pertussis vaccination in protecting newborn infants in England and Wales, 2012-2013. Clin Infect Dis 2015;60:333-7.

[17] Atkins KE, Fitzpatrick MC, Galvani AP, Townsend JP. Cost-effectiveness of pertussis vaccination during pregnancy in the US. American Journal of Epidemiology n.d.

[18] Ozawa S, Mirelman A, Stack ML, Walker DG, Levine OS. Cost-effectiveness and economic benefits of vaccines in low- and middle-income countries: a systematic review. Vaccine 2012;31:96-108.

[19] Atkins KE, Shim E, Pitzer VE, Galvani AP. Impact of rotavirus vaccination on epidemiological dynamics in England and Wales. Vaccine 2012;30:552-64.

[20] Lee BY, Bartsch SM, Willig AM. The economic value of a quadrivalent versus trivalent influenza vaccine. Vaccine 2012;30:7443-6.

[21] Fitzpatrick MC, Hampson K, Cleaveland S, Mzimbiri I, Lankester F, Lembo T, et al. CostEffectiveness of Canine Vaccination to Prevent Human Rabies in Rural Tanzania. Ann Intern Med 2014;160:91-100.

[22] Paternina-Caicedo A, De la Hoz-Restrepo F, Alvis-Guzmán N. Epidemiological and Economic 
Impact of Monovalent and Pentavalent Rotavirus Vaccines in Low and Middle Income Countries: A Cost-effectiveness Modeling Analysis. Pediatr Infect Dis J 2015;34:e176-84.

[23] Gessner BD. The cost-effectiveness of a hypothetical respiratory syncytial virus vaccine in the elderly. Vaccine 2000;18:1485-94.

[24] Berndt ER, Glennerster R, Kremer MR, Lee J, Levine R, Weizsäcker G, et al. Advance market commitments for vaccines against neglected diseases: estimating costs and effectiveness. Health Econ 2007; 16:491-511.

[25] de Vries R, Klok RM, Brouwers JRBJ, Postma MJ. Cost-effectiveness of a potential future Helicobacter pylori vaccine in the Netherlands: the impact of varying the discount rate for health. Vaccine 2009;27:846-52.

[26] Massad E, Coutinho FAB, Chaib E, Burattini MN. Cost-effectiveness analysis of a hypothetical hepatitis C vaccine compared to antiviral therapy. Epidemiol Infect 2009;137:241-9.

[27] Meijboom MJ, Pouwels KB, Luytjes W, Postma MJ, Hak E. RSV vaccine in development: assessing the potential cost-effectiveness in the Dutch elderly population. Vaccine 2013;31:6254-60.

[28] Durham DP, Ndeffo Mbah ML, Medlock J, Luz PM, Meyers LA, Paltiel AD, et al. Dengue dynamics and vaccine cost-effectiveness in Brazil. Vaccine 2013;31:3957-61.

[29] Mirelman AJ, Ballard SB, Saito M, Kosek MN, Gilman RH. Cost-effectiveness of norovirus vaccination in children in Peru. Vaccine 2015;33:3084-91.

[30] O'Brien MA, Prosser LA, Paradise JL, Ray GT, Kulldorff M, Kurs-Lasky M, et al. New vaccines against otitis media: projected benefits and cost-effectiveness. Pediatrics 2009;123:1452-63.

[31] Ward JI, Cherry JD, Chang S-J, Partridge S, Lee H, Treanor J, et al. Efficacy of an acellular pertussis vaccine among adolescents and adults. N Engl J Med 2005;353:1555-63.

[32] United States Census Bureau, Population Estimates n.d. http://www.census.gov/popest/data/historical/2010s/vintage_2013/national.html (accessed September 30, 2015).

[33] Zagheni E, Billari FC, Manfredi P, Melegaro A, Mossong J, Edmunds WJ. Using time-use data to parameterize models for the spread of close-contact infectious diseases. Am J Epidemiol 2008;168:1082-90.

[34] Shim E, Galvani AP. Distinguishing vaccine efficacy and effectiveness. Vaccine 2012:6-11.

[35] Wearing HJ, Rohani P. Estimating the duration of pertussis immunity using epidemiological signatures. PLoS Pathog 2009;5:e1000647.

[36] Gambhir M, Clark T a., Cauchemez S, Tartof SY, Swerdlow DL, Ferguson NM. A Change in Vaccine Efficacy and Duration of Protection Explains Recent Rises in Pertussis Incidence in the United States. PLoS Comput Biol 2015;11:e1004138.

[37] Kanaan MN, Farrington CP. Estimation of waning vaccine efficacy. J Am Stat Assoc 2002;97:38997.

[38] Immunization Schedules. Centers for Disease Control and Prevention 2015. http://www.cdc.gov/vaccines/schedules/index.html (accessed July 20, 2015).

[39] Broder KR, Cortese MM, Iskander JK, Kretsinger K, Slade BA, Brown KH, et al. Preventing tetanus, diphtheria, and pertussis among adolescents: use of tetanus toxoid, reduced diphtheria toxoid and acellular pertussis vaccines recommendations of the Advisory Committee on Immunization Practices (ACIP). MMWR Recomm Rep 2006;55:1-34.

[40] Centers for Disease Control and Prevention (CDC). Updated recommendations for use of tetanus toxoid, reduced diphtheria toxoid, and acellular pertussis vaccine (Tdap) in pregnant women-Advisory Committee on Immunization Practices (ACIP), 2012. MMWR Morb Mortal Wkly Rep 2013;62:131-5.

[41] Elam-Evans LD, Yankey D, Jeyarajah J, Singleton JA, Curtis RC, MacNeil J, et al. National, regional, state, and selected local area vaccination coverage among adolescents aged 13-17 years-United States, 2013. MMWR Morb Mortal Wkly Rep 2014;63:625-33.

[42] Kharbanda EO, Vazquez-Benitez G, Lipkind H, Naleway AL, Klein NP, Cheetham TC, et al. Receipt of pertussis vaccine during pregnancy across 7 Vaccine Safety Datalink Sites. Prev Med 2014;67:316-9.

[43] Goldfarb IT, Little S, Brown J, Riley LE. Utilization of the combined tetanus-diphtheria and 
pertussis vaccine during pregnancy. Am J Obstet Gynecol 2014. doi:10.1016/j.ajog.2014.05.029.

[44] Ding H, Black CL, Ball S, Donahue S, Fink RV, Williams WW, et al. Influenza vaccination coverage among pregnant women--United States, 2014-15 influenza season. MMWR Morb Mortal Wkly Rep 2015;64:1000.

[45] Age and Sex Composition in the United States: 2012. United States Census Bureau 2013. http://www.census.gov/population/age/data/2012comp.html (accessed July 20, 2015).

[46] Sachs J, World Health Organization. Macroeconomics and Health: Investing in Health for Economic Development. Diamond Pocket Books (P) Ltd.; 2001.

[47] Bart MJ, Harris SR, Advani A, Arakawa Y, Bottero D, Bouchez V, et al. Global population structure and evolution of Bordetella pertussis and their relationship with vaccination. MBio 2014;5:e01074.

[48] Warfel JM, Zimmerman LI, Merkel TJ. Acellular pertussis vaccines protect against disease but fail to prevent infection and transmission in a nonhuman primate model. Proc Natl Acad Sci U S A 2014;111:787-92.

[49] Althouse BM, Scarpino SV. Asymptomatic transmission and the resurgence of Bordetella pertussis. BMC Med 2015;13:146.

[50] Thorstensson R, Trollfors B, Al-Tawil N, Jahnmatz M, Bergström J, Ljungman M, et al. A phase I clinical study of a live attenuated Bordetella pertussis vaccine-BPZE1; a single centre, double-blind, placebo-controlled, dose-escalating study of BPZE1 given intranasally to healthy adult male volunteers. PLoS One 2014;9:e83449.

[51] Mielcarek N, Nathalie M, Anne-Sophie D, Dominique R, Julie B, Carine R, et al. Live Attenuated B. pertussis as a Single-Dose Nasal Vaccine against Whooping Cough. PLoS Pathog 2006;2:e65.

[52] Gouw D de, de Gouw D, de. Jonge MI, Hermans PWM, Hans J C, Aldert Z, et al. ProteomicsIdentified Bvg-Activated Autotransporters Protect against Bordetella pertussis in a Mouse Model. PLoS One 2014;9:e105011.

[53] Alvine T, Ganske A, Nilles M, Bradley D. BscF as a vaccine candidate for Bordetella pertussis infection ("Whooping Cough")(VAC9P. 1064). The Journal of Immunology 2015;194:145-144. 


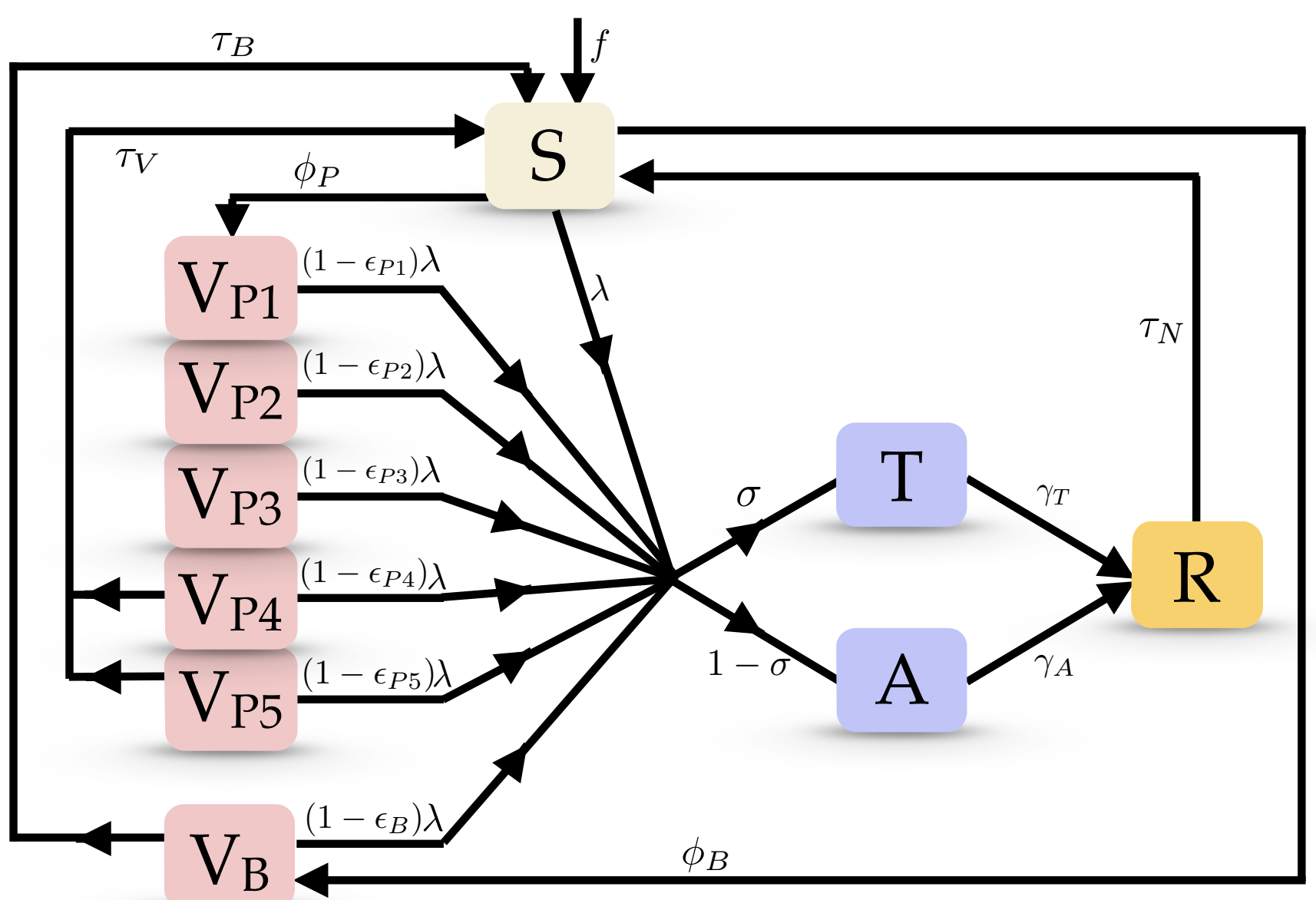


A

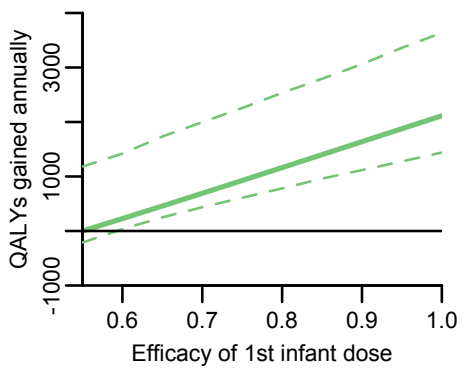

D

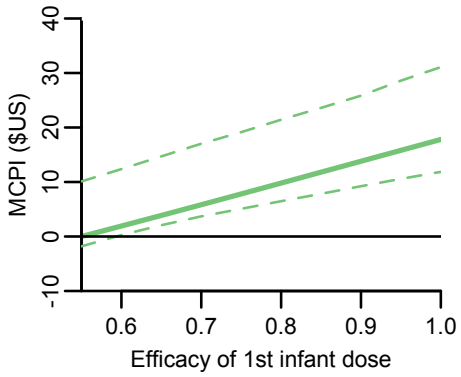

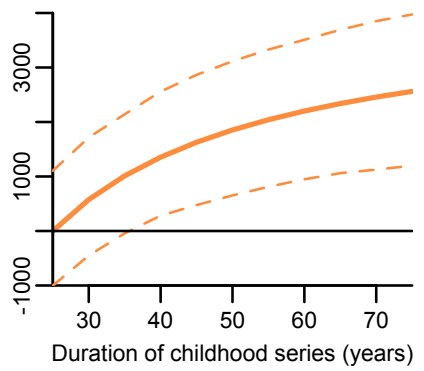

E

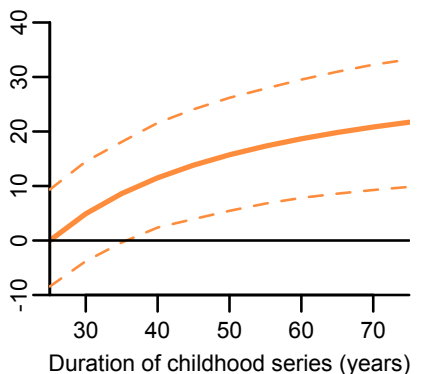

C

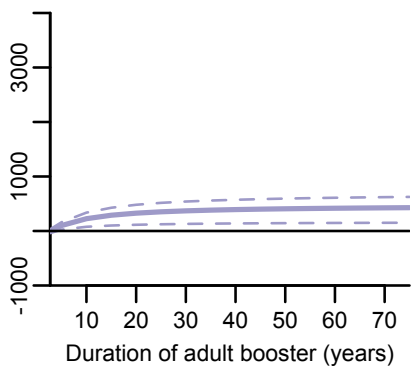

F

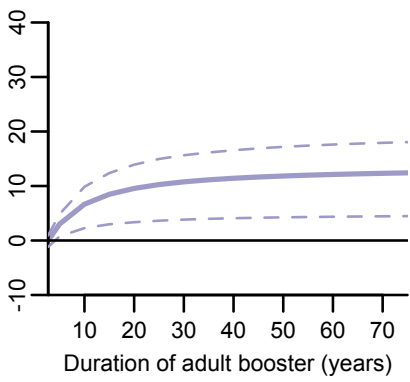


A

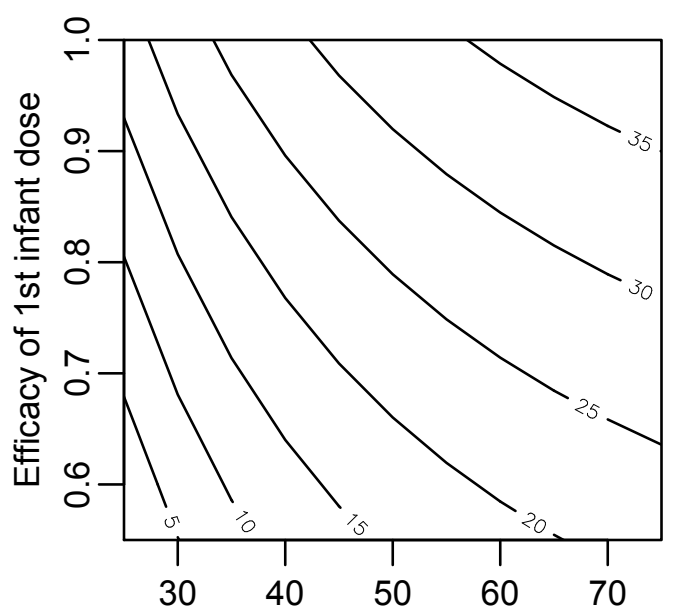

Duration of childhood series (years)

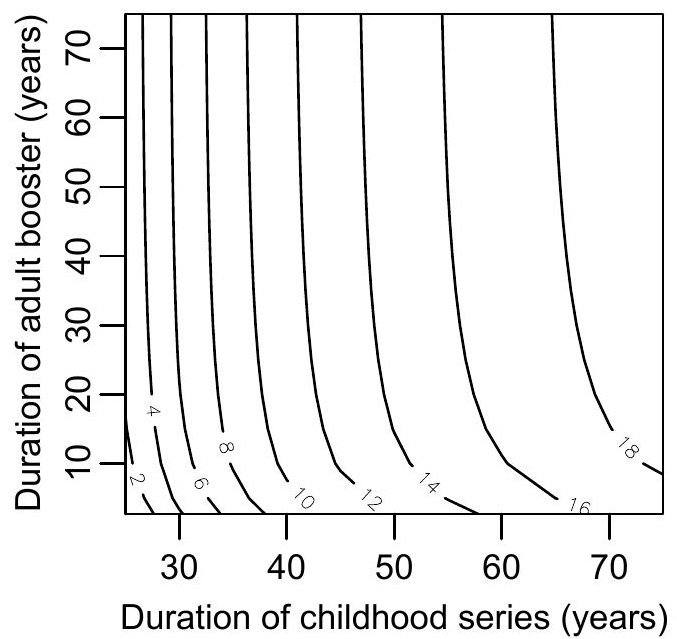


A) 1st Dose Efficacy

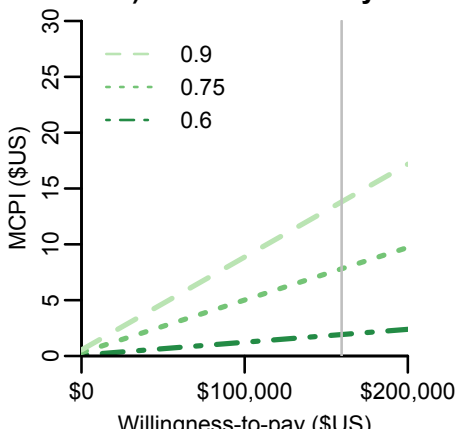

Willingness-to-pay (\$US)
B) Duration of Childhood Series

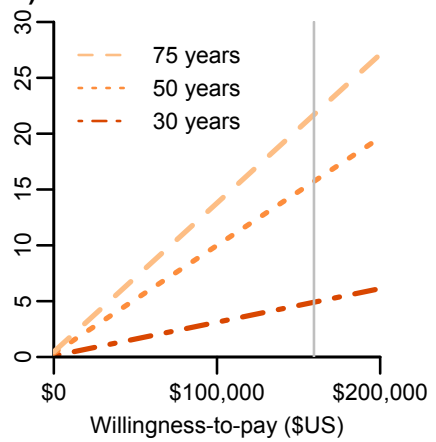

C) Duration of Adult Booster

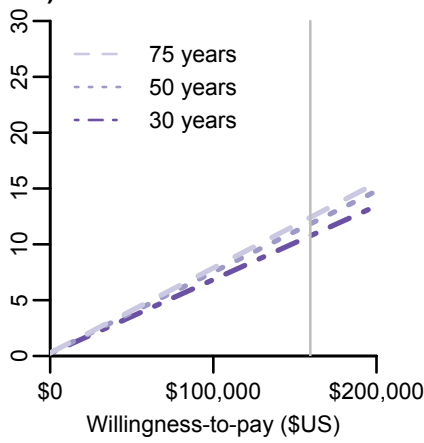




\section{COST-EFFECTIVENESS OF NEXT-GENERATION VACCINES: THE CASE OF PERTUSSIS}

SUPPLEMENTARY MATERIAL

Meagan C. Fitzpatrick, Natasha S. Wenzel, Samuel V. Scarpino, Benjamin M. Althouse, Katherine E. Atkins, Alison P. Galvani, Jeffrey P. Townsend

\section{TABLE OF CONTENTS}

Figure S1: Sensitivity of MCPI to maternal vaccination coverage ..................................

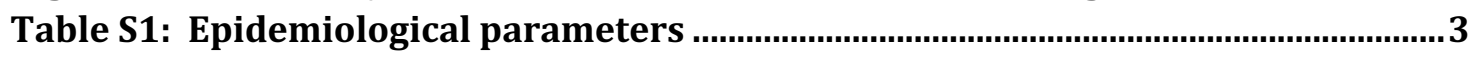

Table S2: Historical Vaccination Coverage Rates ......................................................... 4

Table S3: Health and Economic Outcome Parameters.............................................5

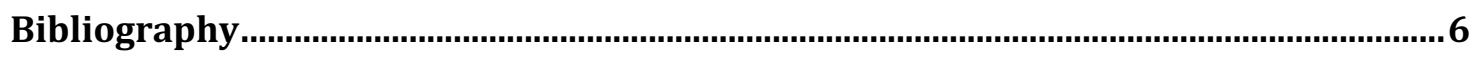




\section{Figure S1: SENSITIVITY OF MCPI TO MATERNAL VACCINATION COVERAGE}

Each line represents the maximum cost-effective price increase (\$US) of a single improvement to the pertussis vaccine across varying values of maternal vaccination coverage. For improvements to the efficacy of the childhood series, the efficacy of all doses in the series improves in tandem with improvement to the first dose.
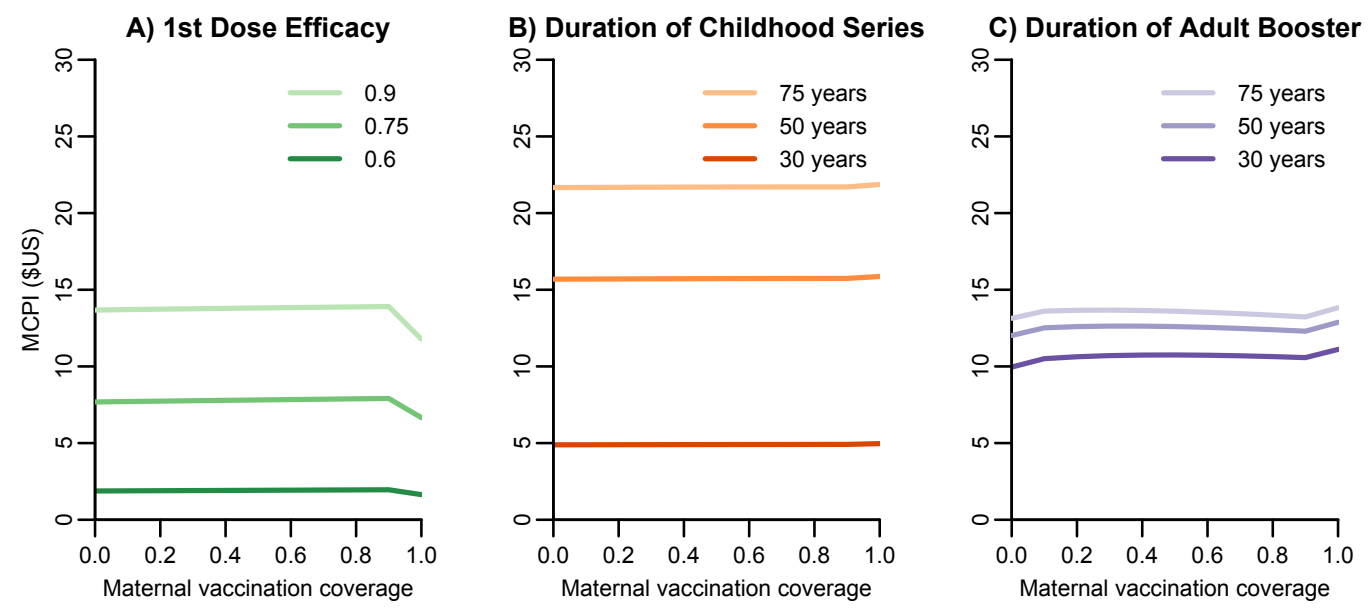
TABLE S1: EPIDEMIOLOGICAL PARAMETERS

\begin{tabular}{|c|c|c|c|}
\hline Parameter & Symbol & Base Case $(95 \% \mathrm{Cl})$ & Reference \\
\hline Birth Rate & $f$ & 0.05 & [1] \\
\hline Efficacy of maternally-acquired antibodies & $m$ & $0.89(0.77-0.93)$ & [1] \\
\hline Probability of infection, given exposure (per minute) & $b$ & $0.0031(0.0024-0.0041)$ & [1] \\
\hline Probability of typical infection, given infection & $\sigma$ & 0.195 & {$[2,3]$} \\
\hline Duration of typical infection (days) & $1 / r_{T}$ & $25(21-28)$ & {$[4,5]$} \\
\hline Duration of atypical infection (days) & $1 / r_{A}$ & $8(4-10)$ & {$[4,5]$} \\
\hline Relative transmissibility of typical infection & & 1 & [1] \\
\hline Relative transmissibility of atypical infection & $\rho$ & 0.1 & [1] \\
\hline Duration of natural immunity (years) & $1 / \tau_{N}$ & 30 & {$[1,6]$} \\
\hline \multicolumn{4}{|l|}{ DTaP } \\
\hline 1st dose efficacy & $\varepsilon_{1}$ & $0.55(0.45-0.62)$ & [7] \\
\hline 2nd dose efficacy & $\varepsilon_{2}$ & $0.75(0.66-0.82)$ & [7] \\
\hline 3rd dose efficacy & $\varepsilon_{3}$ & $0.84(0.79-0.87)$ & [7] \\
\hline 4th/5th dose efficacy & $\varepsilon_{V}$ & $1.00(0.98-1.00)$ & [8] \\
\hline Duration of vaccine-induced immunity & $\tau_{V}$ & $23.5(17.2-35.7)$ & [8] \\
\hline \multicolumn{4}{|l|}{ Tdap } \\
\hline Efficacy & $\varepsilon_{B}$ & $1.00(0.86-1.00)$ & {$[1,9]$} \\
\hline Duration of vaccine-induced immunity & $\tau_{B}$ & $2.7(2.1-3.8)$ & {$[1,9]$} \\
\hline \multicolumn{4}{|l|}{ Reporting Rate of Typical Cases (\%) } \\
\hline$<1$ year old & & 1.38 & {$[1,3,10]$} \\
\hline $1-6$ years old & & 0.93 & {$[1,3,10]$} \\
\hline $7-10$ years old & & 0.45 & {$[1,3,10]$} \\
\hline $11+$ years old & & 0.3 & {$[1,3,10]$} \\
\hline
\end{tabular}


TABLE S2: Historical VACCINATION COVERAge

Coverage compiled from [11,12].

\begin{tabular}{|l|l|l|l|}
\hline Doses & Years & Symbol & Coverage Rates $\mathbf{9 5 \%}$ CI) \\
\hline Doses 1-3, childhood series & $1900-1945$ & $\phi_{P 1-3}$ & 0 \\
\hline & $1946-1994$ & & $70(69-71)$ \\
\hline $1995-$ predictions & & $95(94-96)$ \\
\hline Dose 4, childhood series & $1900-1969$ & $\phi_{P 4}$ & 0 \\
\hline & $1970-1994$ & & $70(69-71)$ \\
\hline & $1995-$ predictions & & $85(84-85)$ \\
\hline Dose 5, childhood series & $1900-1969$ & $\phi_{P 5}$ & 0 \\
\hline & $1970-1994$ & & $70(69-71)$ \\
\hline Adolescent/Adult Booster* & 1995 -predictions & & $95(94-96)$ \\
\hline & 2006 & $\phi_{B}$ & 51.9 \\
\hline & 2007 & & 65.2 \\
\hline & 2008 & 73.7 \\
\hline & 2009 & 81 \\
\hline & $2010-$ predictions & & 85.3 \\
\hline & & & \\
\hline
\end{tabular}

*Booster administered to 12-year-olds starting in 2006, per CDC recommendation [13] 


\section{Table S3: Health and Economic Outcome Parameters}

\begin{tabular}{|c|c|c|c|c|c|c|c|c|}
\hline Age & Outcome & $\begin{array}{l}\text { Probability of } \\
\text { Outcome, as } \\
\text { reported }\end{array}$ & $\begin{array}{l}\text { QALY weight, until } \\
\text { improvement }\end{array}$ & $\begin{array}{l}\text { QALY weight, } \\
\text { improvement to } \\
\text { recovery }\end{array}$ & $\begin{array}{l}\text { Time to } \\
\text { Improvement } \\
\text { (days) }\end{array}$ & $\begin{array}{l}\text { Time to } \\
\text { Recovery }\end{array}$ & $\begin{array}{l}\text { Direct Medical } \\
\text { Cost, US\$2013 }\end{array}$ & References \\
\hline \multirow[t]{5}{*}{ Infant } & $\begin{array}{l}\text { Unknown, } \\
\text { Unreported }\end{array}$ & 0 & 0.9 & 1 & 35 & 75 & 0 & {$[1,14]$} \\
\hline & Outpatient & 0.79 & 0.85 & 0.9 & 35 & 75 & 129 & {$[1,14,15]$} \\
\hline & Hospitalization & 0.19 & 0.58 & 0.9 & 35 & 75 & 8553 & [15-17] \\
\hline & $\begin{array}{l}\text { Neurological } \\
\text { Disease }\end{array}$ & 0.012 & 0.51 & 0.9 & 35 & 75 & 8213 & {$[14,15,17,18]$} \\
\hline & Death & 0.008 & 0 & 0 & NA & NA & 18463 & {$[1,15,18-20]$} \\
\hline \multirow[t]{4}{*}{ Older } & $\begin{array}{l}\text { Unknown, } \\
\text { Unreported }\end{array}$ & 0 & 0.9 & 1 & 21 & 66 & 0 & {$[14,15]$} \\
\hline & $\begin{array}{l}\text { Moderate } \\
\text { Outpatient }\end{array}$ & 0.31 & 0.85 & 0.9 & 21 & 66 & 320 & {$[14,15,17,21]$} \\
\hline & $\begin{array}{l}\text { Severe } \\
\text { Outpatient }\end{array}$ & 0.66 & 0.81 & 0.9 & 21 & 66 & 445 & {$[14,15,17,21]$} \\
\hline & Hospitalization & 0.03 & 0.82 & 0.9 & 21 & 66 & 3435 & {$[17,21]$} \\
\hline
\end{tabular}




\section{BIBLIOGRAPHY}

[1] Atkins KE, Fitzpatrick MC, Galvani AP, Townsend JP. Pertussis vaccination during pregnancy is cost-effective in the US. Am J Epidemiol n.d.

[2] Heininger U. A Controlled Study of the Relationship Between Bordetella pertussis Infections and Sudden Unexpected Deaths Among German Infants. Pediatrics 2004;114:e9-15. doi:10.1542/peds.114.1.e9.

[3] Ward JI, Cherry JD, Chang S-J, Partridge S, Keitel W, Edwards K, et al. Bordetella Pertussis infections in vaccinated and unvaccinated adolescents and adults, as assessed in a national prospective randomized Acellular Pertussis Vaccine Trial (APERT). Clin Infect Dis 2006;43:151-7. doi:10.1086/504803.

[4] Van Rie A, Hethcote HW. Adolescent and adult pertussis vaccination: computer simulations of five new strategies. Vaccine 2004;22:3154-65. doi:10.1016/j.vaccine.2004.01.067.

[5] Coudeville L, Van Rie A, André P. Adult pertussis vaccination strategies and their impact on pertussis in the United States: evaluation of routine and targeted (cocoon) strategies. Epidemiol Infect 2008;136:604-20. doi:10.1017/S0950268807009041.

[6] Wearing HJ, Rohani P. Estimating the duration of pertussis immunity using epidemiological signatures. PLoS Pathog 2009;5:e1000647. doi:10.1371/journal.ppat.1000647.

[7] Quinn HE, Snelling TL, Habig A, Mph M, Chiu C, Spokes PJ, et al. Parental Tdap Boosters and Infant Pertussis: A Case-Control Study. Pediatrics 2014. doi:10.1542/peds.2014-1105.

[8] Misegades LK, Winter K, Harriman K, Talarico J, Messonnier NE, Clark T a, et al. Association of childhood pertussis with receipt of 5 doses of pertussis vaccine by time since last vaccine dose, California, 2010. JAMA 2012;308:2126-32. doi:10.1001/jama.2012.14939.

[9] Koepke R, Eickhoff JC, Ayele RA, Petit AB, Schauer SL, Hopfensperger DJ, et al. Estimating the Effectiveness of Tdap Vaccine for Preventing Pertussis: Evidence of Rapidly Waning Immunity and Differences in Effectiveness by Tdap Brand. J Infect Dis 2014:1-38. doi:10.1093/infdis/jiu322.

[10] Sutter RW, Cochi SL. Pertussis hospitalizations and mortality in the United States, 1985-1988. Evaluation of the completeness of national reporting. JAMA 1992;267:386-91. 
[11] CDC. National and state vaccination coverage among adolescents aged 13-17 years--United States, 2012. MMWR Morb Mortal Wkly Rep 2013;62:685-93.

[12] CDC. Vaccination Coverage in the US Reported via NIS 2013. http://www.cdc.gov/vaccines/statssurv/nis/default.htm\#chart.

[13] Broder KR, Cortese MM, Iskander JK, Kretsinger K, Slade BA, Brown KH, et al. Preventing tetanus, diphtheria, and pertussis among adolescents: use of tetanus toxoid, reduced diphtheria toxoid and acellular pertussis vaccines recommendations of the Advisory Committee on Immunization Practices (ACIP). MMWR Recomm Reports Morb Mortal Wkly Rep Recomm Reports Centers Dis Control 2006;55:1-34.

[14] Lee L, Pichichero M. Costs of illness due to Bordetella pertussis in families. Arch Fam Med 2000;9:989-96.

[15] Lee GM, Murphy T V, Lett S, Cortese MM, Kretsinger K, Schauer S, et al. Cost effectiveness of pertussis vaccination in adults. Am J Prev Med 2007;32:186-93. doi:10.1016/j.amepre.2006.10.016.

[16] Wisconsin State Public Health Department n.d. http://www.dhs.wisconsin.gov/immunization/pertussis.htm.

[17] Lee GM, Salomon JA, LeBaron CW, Lieu TA. Health-state valuations for pertussis: methods for valuing shortterm health states. Health Qual Life Outcomes 2005;3:17. doi:10.1186/1477-7525-3-17.

[18] CDC. Pertussis--United States, 2001-2003. MMWR Morb Mortal Wkly Rep 2005;54:1283-6.

[19] Centers for Disease Control and Prevention. 2013 Final Pertussis Surveillance Report 2014:CS252563A.

[20] Centers for Disease Control and Prevention. 2012 Final Pertussis Surveillance Report. 2013.

[21] Lee GM, Lett S, Schauer S, LeBaron C, Murphy T V, Rusinak D, et al. Societal costs and morbidity of pertussis in adolescents and adults. Clin Infect Dis 2004;39:1572-80. doi:10.1086/425006. 